\title{
PERSPECTIVAS DE REALIZAÇÃO E DESENVOLVIMENTO PESSOAL E PROFISSIONAL EM LICENCIANDOS ${ }^{1}$
}

\author{
Adelar Aparecido Sampaio \\ Universidade Estadual do Oeste do Paraná, Cascavel, Paraná, Brasil \\ Claus Dieter Stobaus \\ Pontifícia Universidade Católica do Rio Grande do Sul, Porto Alegre, Rio Grande do Sul, Brasil \\ Marcio Alessandro Cossio Baez \\ Pontifícia Universidade Católica do Rio Grande do Sul, Porto Alegre, Rio Grande do Sul, Brasil \\ Alvori Ahlert \\ Universidade Estadual do Oeste do Paraná, Cascavel, Paraná, Brasil
}

\begin{abstract}
Resumo
$\mathrm{O}$ artigo apresenta perspectivas pessoais e profissionais de licenciandos, a partir de vivências da formação inicial. É um estudo qualitativo em nível exploratório-descritivo, desenvolvido com 68 formandos dos cursos de Pedagogia, Educação Física e Letras de uma instituição privada do estado do Paraná. Foi utilizado questionário, sendo os dados tratados com o método da análise de conteúdo. Os resultados indicam o desejo de realização pessoal e profissional e de continuidade na profissão, embora fique explícito o pensamento em optar por outra profissão, além de um anseio por melhorias nas condições para o exercício profissional e o aprofundamento de estudos sobre adversidades na escola. Sugerem-se investimentos em processos de intervenções preventivas sobre possíveis fatores indutores do mal-estar docente.
\end{abstract}

Palavras-chave: Formação continuada. Estudantes. Docência.

\section{Introdução}

Os desafios cada vez mais complexos ao exercício da docência, por conta de uma dinâmica social que se apresenta com profundas mudanças (ESTEVE, 1995; 2004), nos obriga a constantemente refletir e repensar a formação de professores no sentido de responder às exigências do contexto. Nesse sentido, destacamos a necessidade de fomentar a formação para essa mudança, iniciando, nos cursos de licenciatura, o preparo e o apoio aos potenciais futuros docentes, investindo num trabalho que os coloque à frente de várias situações desafiadoras que a profissão docente pode lhes apresentar, como destaca Jesus (2002), e possibilitando aprendizagens de competências de atuação, as quais podem repercutir positivamente para o resto da carreira docente.

Urge envidarmos esforços no sentido de otimizar os processos de formação inicial, pois consideramos que essa fase de socialização profissional pode ser determinante para o

\footnotetext{
${ }^{1} \mathrm{O}$ presente trabalho não contou com apoio financeiro.
} 
mal-estar e/ou bem-estar na vida pessoal e profissional do futuro docente. Esta situação tornase mais relevante se avaliarmos como imprescindíveis o bem-estar, a motivação, bem como as perspectivas profissionais do licenciando, potencial futuro docente, para o aprimoramento dos processos de formação.

Conforme destaca Flores (2010), na formação docente, o contexto social e as competências que se reconhecem e se exigem do professor são determinantes, mas, sobretudo, são indispensáveis as oportunidades e os processos de formação proporcionados aos futuros professores. Diante desse contexto, Batista, Pereira e Graça (2012) referem-se a um dos grandes desafios que se coloca às instituições de formação, a necessidade de formar profissionais competentes, com um sentido fortemente positivo do exercício da futura profissão, comprometido com a melhoria das práticas profissionais nos contextos reais de exercício.

Fundamentalmente, cremos que o contexto de formação inicial docente sinaliza a necessidade de entender melhor as situações vivenciais, pessoais e acadêmicas/profissionais do licenciando, principalmente no sentido de contribuir para a prevenção e o controle de situações de mal-estar docente e, da mesma forma, otimizar ações para o desenvolvimento de competências para gerir situações adversas no contexto docente, com vistas ao seu desenvolvimento pessoal e profissional.

Nessa perspectiva, alguns apontamentos resultantes do presente estudo podem servir de referência e trazer importantes elementos à atenção para a questão específica da formação inicial dos professores, em face dos desafios do contexto social atual, rumo ao bem-estar pessoal e profissional.

No intuito de abordar esses elementos, o artigo tem como objetivo apresentar vivências e perspectivas profissionais de potenciais futuros professores a partir de seu envolvimento com o contexto formativo entre a formação inicial acadêmica e suas experiências com o contexto escolar.

\section{O licenciando/docente como pessoa e profissional}

Diversas pesquisas procuram abarcar a temática do estágio de formação docente. De modo específico, as questões do mal-estar e do bem-estar no contexto do licenciando ainda dependem de estudos mais precisos na área. A partir dessa constatação, temos envidado esforços no sentido de melhor compreender essa etapa de formação, principalmente por haver carência de estudos relacionados com esse período. As vivências e os diversos olhares que se entrelaçam nas várias etapas de formação são de grande relevância, pois é a partir desse enredamento que os referenciais pessoais e profissionais vão se impregnando na vida do potencial futuro professor (SAMPAIO, 2014).

A formação docente, de acordo com Nóvoa (1992), está ligada de modo direto ao pressuposto da indivisibilidade do professor como pessoa e profissional, com características formativas de seus vários momentos de vida. Assim, pode-se afirmar que as vivências do contexto social, familiar e escolar em que está inserido contribuem para sua formação pessoal e profissional. Por isso, a formação docente é um processo social e não pode ser separada do desenvolvimento pessoal (MOROSINI; COMARÚ, 2009). A mesma ênfase é destacada pelas autoras ao considerarem prioritário o desenvolvimento do professor indissociado de sua pessoa.

Grillo (2004), da mesma forma, manifesta que o ponto inicial para a análise da figura do professor como pessoa e profissional é a sua inseparabilidade. A identidade do professor, para a autora, define-se num equilíbrio entre as características pessoais e profissionais, do que se conclui que suas ações traduzem a plenitude de sua pessoa, decorrendo também (JANUÁRIO, 2012) de suas experiências pretéritas e durante o período de formação inicial, quando se exercitam as várias competências pessoais, de forma contínua e multilateral. 
As reflexões sobre o estudo do professor como pessoa são evidenciadas, há décadas, por Mosquera (1977), que destaca que ele é primeiramente um ser humano, com seus potenciais energéticos, suas ideias, estruturações mentais e limitações. Como pessoa, diz o autor, o professor tem um passado histórico que se mede não apenas por um relato subjetivo, mas também, e principalmente, pelas experiências realizadas e pelas ações que conseguiu estabelecer através de comportamentos sucessivos. Em suma, experiências vividas no contexto pessoal e profissional convergem e contribuem decisivamente para a constituição da pessoa do professor.

Apoiado em Giles, Mosquera (1977) enfatiza que o ser humano deve ser pensado em sua totalidade e, para isso, é necessário visualizar o mundo que o rodeia e com o qual mantém um constante diálogo, sendo importante para o desenvolvimento da personalidade e para um processo educacional mais aberto e adequado.

Assim, nos lembra o autor da importância em considerar, refletir sobre elas e até revisar as considerações sobre as representações sociais que os estudantes dos cursos de licenciatura desenvolvem sobre o trabalho no processo de sua formação. Seus pensamentos e ações, de acordo com Mosquera, resultam dos modos de pensar e agir não somente com seus colegas e professores formadores, mas também sobre e com o meio; não são atividades isoladas e que "nascem" das elucubrações da vida, mas, sim, situações constituídas pelas experiências humanas que modificam o sujeito e, ao mesmo tempo, modificam o meio em que ele está inserido.

Essas considerações nos dão conta de que, nas interações do contexto de socialização profissional, há também as relações com o meio, que transformam a formação docente em uma atividade humana permeada por subjetividades. Santos et al. (2012) elencam possibilidades práticas de construção pessoal de docentes, baseado numa perspectiva de formação pela autoformação. Salientam, desse modo, a importância da autonomia, do trabalho cooperativo, do bem-estar docente, da autoimagem e da autoestima positivas no desenvolvimento do autoconhecimento, representando uma estética profissional visível na práxis.

Sousa (2006) nos lembra que a formação é um movimento constante de construção e reconstrução da aprendizagem pessoal e profissional, envolvendo saberes, experiências e práticas. Essas considerações não são recentes, e Mosquera (1977) já nos recordava de que, como pessoa, o professor tem um passado histórico que não se mede apenas por um relato subjetivo, mas principalmente pelas experiências que realizou e pelas ações que conseguiu desencadear através de comportamentos sucessivos.

Nesse sentido, a história do indivíduo torna-se importante e necessária e parece ser fundamental, para entender o significado da sua profissão, considerar todo o enredamento das experiências do lado pessoal (MOSQUERA, 1978), uma vez que ele encontra-se imerso em uma rede de relações sociais e enraizado em um determinado terreno histórico (VÁSQUEZ, 2007). Essas considerações nos dão conta de que, nas interações do contexto de formação profissional, as relações com o meio transformam a formação docente em uma atividade humana permeada por subjetividades.

Santos et al. (2012) elencam possibilidades práticas de construção pessoal de docentes, baseado numa perspectiva de formação pela autoformação. Salientam, desse modo, a importância da autonomia, do trabalho cooperativo, do bem-estar docente, da autoimagem e da autoestima positivas no desenvolvimento do autoconhecimento, representando uma estética profissional visível na práxis. Assim, através das inúmeras vivências no percurso da vida, os autores destacam que o ser humano vai configurando sua autovaloração, muito ligada ao contexto social em que vive. Na mesma linha, Antunes (2007) destaca que as vivências sociais determinam a construção do ser humano em cada pessoa.

No que se refere à formação e ao desenvolvimento profissional, para Nóvoa (1992), deve-se estimular uma perspectiva crítico-reflexiva, no sentido de fornecer aos professores os 
meios de um pensamento autônomo e que facilite as dinâmicas de autoformação participada. Estar em formação implica um investimento pessoal, um trabalho livre e criativo sobre os percursos e os projetos próprios, com vistas à construção de uma identidade, que é também uma identidade profissional. É necessário, por isso, (re)encontrar espaços de interação entre as dimensões pessoais e profissionais, permitindo aos professores apropriar-se dos seus processos de formação e dar-lhes um sentido no quadro das suas histórias de vida.

Para isso, conforme Nóvoa, é importante valorizar paradigmas de formação que promovam a preparação de professores reflexivos, que assumam a responsabilidade do seu próprio desenvolvimento profissional e que participem como protagonistas na implementação das políticas educativas, pois o profissional competente tem capacidades de autodesenvolvimento reflexivo.

Em face desses desafios, Nóvoa (1992) percebe que a dinamização de dispositivos de investigação-ação e de investigação-formação pode condensar a apropriação pelos professores dos saberes que são chamados a mobilizar no exercício da sua profissão. Nesse espaço e nessa perspectiva, complementa o autor, ganha terreno o triplo movimento sugerido por Schön (2000) - conhecimento na ação, reflexão na ação e reflexão sobre a ação e sobre a reflexão na ação -, avultando no quadro do desenvolvimento pessoal e consolidando-se no terreno profissional.

A adequação dos enfoques formativos, no sentido de contribuir para a motivação do licenciando e ao desenvolvimento de estratégias diante dos desafios emergentes do contexto laboral docente, é uma demanda recorrente. Embora desafiadoras, há evidências e experiências que ganham destaque, sinalizando a possibilidade de aprendizagem de formas de prevenção e competências para o enfrentamento de situações adversas que envolvem a docência (JESUS, 1998; 2002; 2007).

Parece-nos um importante passo, no processo de promoção da formação profissional para a docência, o direcionamento e o desenvolvimento de planos a partir de programas específicos de intervenção e da própria otimização da formação inicial, voltados a diminuir o malestar e aumentar os níveis de motivação e bem-estar pessoal e profissional para a profissão docente. No sentido de apresentar alternativas de formação nessa perspectiva, a discussão sobre os resultados do estudo, a seguir, procura delinear algumas possibilidades.

\section{Metodologia}

O estudo qualitativo em nível exploratório-descritivo foi desenvolvido no final da formação pedagógica em 2012, realizado com licenciandos do último período dos cursos de Pedagogia, Educação Física e Letras de uma instituição privada do estado do Paraná.

Os sujeitos participantes constituíram uma amostra de 68 alunos, sendo 53 do sexo feminino e 15 do sexo masculino, com idades compreendidas entre 19 e 46 anos, todos cursando o último ano dos seus respectivos cursos e sem ainda ter exercido docência como professor titular. Do total da amostra, 20 eram do curso de Pedagogia, 28 do curso de Educação Física e 20 do curso de Letras.

O instrumento de coleta de dados foi um questionário com questões abertas, construído a partir do estudo de Jesus (1998), pretendendo analisar os desenvolvimentos de variáveis cognitivo-motivacionais.

Para validação do instrumento, partimos do planejamento e da formulação das questões para obter as informações necessárias, ordenando as perguntas e o aspecto visual do questionário, seguido de testagem, utilizando-se de uma pequena amostra, o que nos permitiu corrigir alguns problemas levantados e sua reorganização. Suas respostas foram tratadas na proposta de Bardin (2011), sendo substituída a identificação dos licenciandos, de modo a preservar o sigilo de suas identidades, pelos números de " 1 " a " 68 " antecedidos das letras "S" de 
sujeito e sucedidos das letras que identificam seus cursos: P para Pedagogia, EF para Educação Física e L para Letras.

Para o presente artigo, apresentamos especificamente a categoria que procurou apresentar as perspectivas de realização e desenvolvimento profissional durante o período de formação nos cursos de licenciatura, a qual surgiu a partir do processo de leitura e releitura das respostas, sendo possível categorizar por unidades semelhantes, formando a categoria final.

O estudo foi aprovado pela Comissão Científica, em 2012, sob o número 079/2012 e pelo Comitê de Ética da PUCRS-CEP sob o número 09470612.7.0000.5336, contando com o Termo de Consentimento Livre e Esclarecido (TCLE) e respeitando os aspectos éticos de pesquisas com pessoas.

\section{Resultados e discussão}

Os resultados sobre as perspectivas de realização e desenvolvimento pessoal e profissional partem de considerações sobre as vivências de formação e da forma com que os licenciandos visualizam antecipadamente suas futuras carreiras como docentes para esse efeito.

Nessse sentido, as respostas apresentadas foram elencadas em subcategorias, das quais destacamos, primeiramente, os apontamentos dos licenciandos que indicam uma maior inclinação sobre a dedicação à vida pessoal, realização pessoal e profissional (ser professor) $e$ desejo de boa atuação e reconhecimento profissional.

Dentre as respostas mais citadas, destacamos: "Vou ter mais tempo para minha família, pois mesmo a carreira do professor ser árdua pretendo ter tempo para cuidar bem da minha vida pessoal" (S62L); "Sempre pensei em ter meu próprio negócio" (S14P); "Quero ser um profissional bem estruturado para que minha vida pessoal seja tranquila" (S23EF); "Ser uma pessoa realizada na vida em todos os sentidos" (S7P); "Realizando o desejo de ser um grande e bom professor" (S10P); "Que eu seja um excelente professor e que eu seja bem visto pelos meus colegas e alunos" (S17P); "Pretendo me dedicar para ser um profissional inovador" (S5P); "Ter um bom emprego e poder me relacionar bem com os colegas" (S 7P); "Um profissional de sucesso, quero sempre estar me atualizando e dando o melhor de mim" (S28EF).

O reconhecimento profissional é de grande importância para o desenvolvimento pessoal e profissional. Nesse sentido, Mosquera (1977) cita as necessidades do ser humano, o desenvolvimento do self como fundamental para o desenvolvimento da pessoa e, consequentemente, da sua autoimagem e autoestima. Para o autor, a autoestima provém da aprovação dos outros membros do seu grupo de referência ou de grupos mais amplos e, a partir deste inter-relacionamento, estrutura-se o status que o indivíduo tem na comunidade ou na sociedade, enquanto a autoimagem se desenvolve e amadurece através da aprendizagem que o indivíduo desenvolve em contato com seu ambiente. No que tange aos licenciandos de Educação Física, a busca pelo equilíbrio entre a vida pessoal e profissional e o alcance pelo sucesso profissional são destacados pelos sujeitos como elementos de maior significação.

Sobre o "desejo de continuar na profissão docente", a maioria (34) das 59 respostas recebidas nesse grupo indica uma perspectiva de continuidade e desenvolvimento profissional na docência ao longo da carreira, das quais destacamos: "Meu desejo de ser docente é crescente" (S2P); "Mesmo com dificuldades vou continuar na profissão" (S12P); "Quero ainda me especializar ou cursar outro curso na área" (S18P); "Sinto que escolhi o melhor caminho" (S25EF); "Minha formação está sendo importante, mas sinto que preciso melhorar [...] tenho interesse em fazer uma especialização e aprender mais" (S24EF). Embora considerem, ao final de sua formação, que seu curso foi um espaço importante para adquirir conhecimentos, sentem necessidade de ampliar sua formação, prolongando seu aperfeiçoamento profissional como forma de satisfação pessoal e profissional.

De acordo com Paz (2007), o papel da formação profissional constitui importante ele- 
mento para a construção de significados e representações para a docência, para o fazer do professor, interligados às dimensões pessoal e social, em processo contínuo de formação.

A socialização profissional docente, nesse sentido, implica compreender o processo constitutivo de sua identidade profissional e entender o modo como os potenciais futuros professores interpretam a atividade docente e, consequentemente, direcionam suas ações na prática educacional. Assim, consideramos necessário que o processo formativo se volte para as especificidades da formação do potencial futuro docente, alinhado com os reais desafios do cotidiano, numa perspectiva realista e otimista da profissão, primando pelo seu desenvolvimento profissional.

Por outro lado, o "pensamento em optar por outra profissão" foi muito marcante nas respostas dos licenciandos, como evidenciado em 25 respostas, das quais elencamos: "O quanto antes quero mudar de área" (S37L); "Iniciei com grande vontade de seguir carreira, porém hoje, penso que esta área não é tão promissora considerando o cenário atitudinal" (S21EF); "Já pensei em outra profissão, por causa do salário" (S11P).

É muito evidente nos relatos que os projetos de futuro aparecem carregados de idealização e de sentimentos de realização profissional para a maioria dos licenciandos. No entanto, as evidências de insegurança e desmotivação profissional são muito presentes em suas respostas, principalmente no campo da Educação Física, como reportam: "Quero fazer outro curso superior e trabalhar em outra área" (S22EF); “Após os estágios perdi um pouco a vontade de trabalhar na licenciatura" (S29EF). Nesse sentido, é coerente destacar a necessidade de um olhar atento às condições laborais no contexto de intervenção dos professores, em particular, da Educação Física. Parece-nos que a interação com o contexto escolar e as adversidades que a Educação Física enfrenta, de certo modo, antecipam um sentimento de desmotivação e projeto de abandono da carreira docente.

Analisando essas respostas dadas às questões, percebemos que esse grupo não deseja continuidade na profissão docente. Diante deste diagnóstico, podemos inferir que as vivências pessoais e de formação não lhes tenham permitido ou proporcionado um gosto pela prática docente ou, ainda, que a profissionalização pela qual estão passando não esteja estruturada de modo a voltar-se para o ensino e a aprendizagem da competência docente.

Esse projeto de abandono ou de permanência na profissão docente, conforme destacam Farias e Nascimento (2012), é delineado por diferentes trajetórias em momentos distintos da carreira. De acordo com Santini (2004), as vivências subjetivas de desgaste profissional experimentadas durante a carreira podem desembocar em sentimentos depressivos e em fadiga crônica. Assim, o projeto de abandono manifestado pelos licenciandos participantes do estudo, justamente num período que tem se configurado como um dos mais importantes estágios do processo de formação de professores, acende uma luz de alerta às políticas de formação docente.

Para Jesus (2002), a formação em estágio inicial é a fase em que os potenciais futuros professores sentem maior necessidade de aprendizagem, estando mais suscetíveis às correções e sugestões, sendo, talvez, o único período do percurso profissional em que está institucionalmente previsto que haja acompanhamento e orientação. Provavelmente, muitos que abandonam a profissão docente nesse estágio poderiam ter potencial para serem eficazes se tivessem sido mais encorajados, apoiados e preparados para a prática profissional.

Ito e Soares (2008) apresentam resultados sobre as perspectivas de formandos no que diz respeito à realização profissional, nos quais destacam a ênfase na insegurança em relação ao futuro profissional, como se preparar para conseguir emprego, em qual área trabalhar como preocupações a curto e médio prazos. No estudo referido, a estabilidade financeira foi mencionada como pré-requisito para a constituição familiar mais em longo prazo. O prazer no trabalho, por sua vez, foi considerado mais importante do que a alta remuneração.

Nóvoa (2007) também relata que, nos últimos tempos, a sociedade lançou para dentro 
da escola múltiplos afazeres que foram sendo incorporados pelos professores, o que, consequentemente, tem criado dificuldades para a definição de prioridades. Muitas vezes, as dificuldades em reagir diante das adversidades e dos dilemas cotidianos e da pressão exercida sobre o seu trabalho e sua vida podem gerar conflitos na ação do professor, já que ele necessita desenvolver funções diversificadas diariamente. Desse modo, é possível que muitos professores pensem em desenvolver outras atividades, sem relação com o meio escolar, ou busquem alternativas, com o intuito de se distanciar do trabalho,

Sobre o questionamento "como é que o bem-estar para a profissão docente poderia ser aumentado?", recebemos respostas diversas, principalmente em torno de reivindicações de melhorias de condições para o exercício profissional e do aprofundamento de estudos sobre adversidades vivenciadas na escola, indicadas pelos licenciandos, das quais citamos: "Sinto falta de cursos que nos preparem um pouco melhor em como lidar com os alunos na questão da indisciplina" (S68L); "A educação está muito atrasada em relação ao nível tecnológico dos alunos" (S62L); "Trabalhar com cursos sobre como enfrentar a realidade da escola" (S61L); "Os governantes deveriam valorizar mais os professores e investir mais na Educação" (S55L);"Falta trabalhar mais a parte prática, como lidar com as situações do dia a dia" (S33EF). Os licenciandos em Educação Física ainda destacam sobre a necessidade de "maior valorização e reconhecimento social dos professores". Como exemplo, destacamos os relatos: "[...] infelizmente essa profissão está muito desvalorizada" (S28EF); "Com maior respeito dos alunos aos professores" (S37EF).

Diversos fatores concorrem para o bem-estar/mal-estar docente. Dentre eles, Jesus (1998) distingue três planos: o sociopolítico, o da formação inicial e continuada e o da atuação dos professores, que devem ser objeto de atenção para que se melhorem a qualidade de vida e de trabalho dos professores.

$\mathrm{Na}$ esfera da formação inicial e continuada, temos verificado resultados importantíssimos na prevenção e no controle do mal-estar, assim como na promoção do bem-estar docente, no aumento significativo de níveis de autoimagem e autoestima na profissão docente, a partir de programas específicos desenvolvidos no Brasil e em Portugal. Tais intervenções na formação educacional propiciaram aprendizagens significativas, como se anuncia em diversos trabalhos (JESUS, 1998, 2002, 2007; JESUS e ESTEVE, 2000; SAMPAIO, 2008; JESUS et al., 2011; 2012). Essas referências destacam o auxílio aos docentes no desenvolvimento de competências, qualidades e estratégias para fazer frente às adversidades, contribuindo para a promoção do bem-estar profissional e pessoal.

De modo a prevenir o "choque com a realidade", fator descrito como um dos principais motivos para a desmotivação e forte contribuinte para o mal-estar docente em estágio inicial (ESTEVE, 1994), salientamos a importância de envidar esforços no sentido de promover e otimizar ações específicas no contexto formativo nos cursos de licenciatura, de forma adaptada, pois, segundo Jesus (2007), é preferível um "choque com a perspectiva", no sentido de fornecer um panorama mais realista da profissão docente, conjugando esse modelo com uma perspectiva otimista e salientando também os aspectos positivos, os bons exemplos e as possíveis experiências agradáveis da docência.

Esteve (1994) também destaca, nesse sentido, a necessidade de formar docentes com destreza suficiente para enfrentar esses desafios, reconhecendo a sua existência. $\mathrm{O}$ autor defende a ideia que a formação deve adaptar-se constantemente à realidade, conforme o que Nóvoa (1992) destaca como "gestão do imprevisível" ou do "espaço de incerteza" que, segundo o autor, caracteriza atualmente a sala de aula.

Quando analisamos as respostas dos sujeitos que pensam em não exercer a docência como atividade profissional, é nítida a descrença na profissão por conta da desvalorização social. Para Gatti (2010), atualmente, os graves problemas no que diz respeito à aprendizagem escolar em nossa sociedade acarretam enormes desafios aos cursos de licenciatura no 
Brasil.

Para a autora, múltiplos fatores convergem nesse sentido: as políticas educacionais postas em ação; o financiamento da Educação Básica; aspectos das culturas nacional, regionais e locais; hábitos estruturados; a naturalização em nossa sociedade da situação crítica da aprendizagem efetiva de amplas camadas populares; as formas de estrutura e gestão das escolas; formação dos gestores; as condições sociais e de escolarização de pais e mães de alunos das camadas populacionais menos favorecidas, e, também, a condição do professorado: sua formação inicial e continuada, os planos de carreira e salário dos docentes da educação básica, as condições de trabalho nas escolas.

As manifestações sobre o "desejo de vínculo estável no exercício da profissão" figuram entre os principais apontamentos, conforme relatam: "Eu desejo conseguir passar em concurso e me efetivar em uma escola" (S39L); "Para o futuro penso em passar em concurso para poder exercer um trabalho duradouro em alguma escola" (S33EF).

Devido à maior segurança e à possibilidade de exercer um trabalho contínuo na escola, o desejo de vínculo estável sinaliza a importância de movimentar ações efetivas para a consolidação de planos de carreira docente com vistas a aumentar o poder de atração dos cursos de licenciatura no Brasil.

Nessa direção, se destacam os relatos dos licenciandos em Educação Física voltados para ações do próprio sistema escolar no sentido de promover maior interesse por parte dos alunos nos cursos de licenciatura, como descrevem: "Acredito que alterações no sistema escolar deveriam acontecer para um maior interesse por parte dos alunos nos cursos de licenciatura" (S28EF); "Motivar o ingresso nos cursos de licenciatura" (S21EF).

Sobre essas evidências, Gatti (2010), a respeito da atratividade da profissão docente, a qual perdeu força nos últimos anos, mesmo considerando a necessidade de envidar esforços sobre um conjunto de fatores, salienta a importância em chamar a atenção para a questão específica da formação inicial dos professores, o que envolve diretamente as instituições de ensino superior, em especial as universidades.

Além disso, nossas experiências nos oferecem pistas sobre a relevância das interações com a Educação Básica, especificamente as que envolvem as práticas de ensino, as quais podem propiciar ganhos para a formação do licenciando na sua futura atuação de forma mais ajustada às necessidades do contexto educativo.

Em suma, maiores níveis de motivação para a profissão docente, que devem estar baseados em metas, expectativas de eficácia e de possibilidades concretas de realização de suas ações com sucesso, mais reais e alcançáveis. São elementos que desafiam a formação inicial docente rumo a perspectivas de desenvolvimento pessoal e profissional.

\section{Considerações finais}

Constatamos, no processo de formação do potencial futuro professor, a forte influência das vivências do contexto formativo acadêmico, que, de certa forma, antecipa um sentimento de desmotivação sobre a profissão docente, por conta da desvalorização social e dos problemas contextuais que a docência enfrenta. Esta realidade sinaliza a possibilidade de desistência da profissão, fato demonstrado pelo considerável número de licenciandos que manifestam o desejo por outra profissão, descrentes quanto ao seu futuro desenvolvimento profissional e à perspectiva de sucesso.

Desse modo, destacamos a necessidade impreterível de investir na formação inicial, principalmente em processos de intervenções preventivas sobre possíveis fatores indutores de mal-estar docente, passando pelo desenvolvimento dos recursos cognitivos e comportamentais dos potenciais futuros professores, pois esse período inicial de formação baliza a motivação ao exercício da profissão e é de fundamental importância para o desenvolvimento pessoal e 
profissional, que se refletirá por toda a carreira do professor.

Ainda é fundamental que sejam desencadeadas ações interventivas no plano sociopolítico no sentido de investir para atrair potenciais futuros professores com maior valorização profissional e imagem social da profissão, em melhores condições para o exercício da docência, além de fomentar melhores qualificações no sentido continuado. Também consideramos importante destacar uma postura responsável e crítica por parte do potencial professor pelo seu próprio desenvolvimento profissional diante dos constantes desafios do contexto laboral.

\title{
ACHIEVEMENT PROSPECTS AND PERSONAL AND PROFESSIONAL DEVEL- OPMENT AND IN UNDERGRADUATE STUDENTS
}

\begin{abstract}
The article presents personal and professional perspectives of undergraduate students, from experiences of initial training. It is a qualitative study of exploratory and descriptive level, developed with 68 students of Education, Physical Education and Arts of a private institution of the State of Paraná. A questionnaire was used, and the data processed with content analysis. The results indicate the desire for personal and professional fulfillment and continuity in the profession, although explicit thought to opt for another profession, improved conditions for professional practice and further studies of adversities in school. It is suggested investments in preventive interventions processes on possible inducing factors of teacher malaise.

Keywords: Continued Education. Students. Teaching.

\section{PERSPECTIVAS DE REALIZACIÓN Y DESARROLLO PERSONAL Y PROFESIO- NAL EN LICENCIANDOS}

\section{Resumen}

Este artículo presenta perspectivas personales y profesionales de licenciandos, a partir de experiencias en la formación inicial. Es un estudio cualitativo en nivel exploratorio-descriptivo, desarrollado con 68 graduandos de los cursos de Pedagogía, Educación Física y Filología de una institución privada del Estado de Paraná. Se usó un cuestionario y los datos se analizaron a partir de su contenido. Los resultados indican el deseo de realización personal y profesional y de continuidad en la profesión, aunque esté claro el pensamiento explícito de optar por otra profesión, además de eso se identificó el anhelo de mejorías en las condiciones para el ejercicio profesional y el perfeccionamiento de estudios relacionados a las adversidades de la escuela. Se sugiere inversiones en los procesos de intervenciones preventivas sobre los posibles factores inductores de malestar docente.

Palabras clave: Educación Continua. Estudiantes. Docencia

\section{Referências}

ANTUNES, D. D. Relatos significativos de professores e alunos e sua autoimagem e autoestima. 2007. 189 f. Dissertação (Mestrado em Educação) - Programa de Pós-Graduação em Educação, Pontifícia Universidade Católica do Rio Grande do Sul, 2007.

BATISTA, P. M. F.; PEREIRA, A. L.; GRAÇA, A. B. dos S. A (re)configuração da identidade profissional no espaço formativo do estágio profissional. In: NASCIMENTO, J. V. do N.; FARIAS, G. O. (Org.). Construção da identidade profissional em educação física: da formação à intervenção. Florianópolis: Ed. da UDESC, 2012. 
BARDIN, L. Análise de conteúdo. 3. ed. Lisboa: Edições 70, 2011.

ESTEVE, J. M. O mal-estar docente. 3. ed. Barcelona: Paidós, 1994.

Mudanças sociais e função docente. In: NÓVOA, A. Profissão professor. 2. ed. Portugal: Porto Editora, 1995.

A terceira revolução educacional: a educação na sociedade do conhecimento. São Paulo: Moderna, 2004.

FARIAS, G. O.; NASCIMENTO, J. V. Construção da identidade profissional: metamorfoses na carreira docente em Educação Física. In: NASCIMENTO, J. V. do N.; FARIAS, G. O. (Org.). Construção da identidade profissional em educação física: da formação à intervenção. Florianópolis: Ed. da UDESC, 2012.

FLORES, M. A. Reflexões em torna da formação inicial de professores. Educação, Porto Alegre, v. 33, n. 3, p. 182-188, set./dez. 2010. Disponível em:< http://revistaseletronicas.pucrs.br/ojs/index.php/faced/article/viewFile/8074/571모. Acesso em: 21 fev. 2015.

FREIRE, Paulo. Educação como prática da liberdade. Rio de Janeiro, Paz e Terra, 2009.

GATTI, B. A. Formação de professores no Brasil: características e problemas. Educação Soc., Campinas, v. 31, n. 113, p. 1355-1379, out./dez. 2010. Disponível em: <http://www.scielo.br/pdf/es/v31n113/16.pdf>. Acesso em: 25 mar. 2015.

GRILLO, M. O professor e a docência: o encontro com o aluno. In: ENRICONE, Délcia. Ser professor. Porto Alegre: EDIPUCRS, 2004.

ITO, L. H.; SOARES, D. H. P. Projeto do futuro e identidade: um estudo com estudantes formandos. Aletheia, n. 27, p. 65-80, jan./jul., 2008.

JANUÁRIO, C. O desenvolvimento profissional: a aprendizagem de ser professor e o processo de rotinização das decisões pré-interativas em professores de Educação Física. In: NASCIMENTO, J. V. do N.; FARIAS, G. O. (Org.). Construção da identidade profissional em educação física: da formação à intervenção. Florianópolis: Ed. da UDESC, 2012.

JESUS, S. N. de. Bem-estar dos professores: estratégias para realização e desenvolvimento profissional. Porto: Porto Editora, 1998.

. Pistas para o bem-estar dos professores. Educação- PUCRS, Porto Alegre, ano 26, n. 43, p. 123-132, 2001.

Perspectivas para o bem-estar docente. Porto: ASA Editores, 2002. diação, 2007.

Professor sem stress: realização profissional e bem-estar docente. Porto Alegre: MeJESUS, S. N.; ESTEVE, J. M. Programa de formación para la prevención del mal estar docente. Revista Galego-Portuguesa de Psicoloxía e Educación, v. 4, 43-54, 2000.

JESUS, S. N. de; SANTOS, J. C. V. Desenvolvimento profissional dos professores. Educação, PUCRS, ano 26, v. 1, n. 52, p. 39- 58, jan./abr. 2004. 
JESUS, S. N. de; MOSQUERA, J. J. M.; STOBAUS, C. D.; SAMPAIO, A. A.; REZENDE; M.; MASKARENHAS, S. Avaliação da motivação e do bem/mal-estar dos professores: estudo comparativo entre Brasil e Portugal. Amazônica. Revista de Psicopedagogia, Psicologia Escolar e Educação, v. 7, p. 7- 18, 2011.

JESUS, S. N. de; LOBO, P.; MARTINHO, J.; CARA-LINDA, I.; LEAL, A. R.; SAMPAIO, A. A.; STOBAUS, C. D.; MOSQUERA, J. J. M. Impacto da formação sobre a motivação e o bem-estar: estudos realizados com professores em Portugal e Brasil. In: REBOLO, F.; TEIXEIRA, L. R. M. T.; PERRELLI, M. A. de S. Docência em questão. Campinas: Mercado de Letras, 2012.

MOROSINI, M. C.; COMARÚ, P. A. A dimensão profissional docente: questões do nosso tempo. In: ENRICONE, D. Professor como aprendiz. Saberes docentes. Porto Alegre: EDUPUCRS, 2009. p. 62- 92.

MOSQUERA, J. J. M. Psicodinâmica do Aprender: 2. ed. Porto Alegre: Sulina, 1977.

O professor como pessoa. Porto Alegre: Sulina, 1978.

Vida adulta: personalidade e desenvolvimento. 3. ed. Porto Alegre: Sulina, 1983.

MOSQUERA, J. J. M.; STOBÄUS, C. D . Auto-imagem, auto-estima e realização: qualidade de vida na universidade. Psicologia, Saúde \& Doenças, v. 7, n. 1, p. 83-88, 2006.

NÓVOA, A. Os professores e as histórias da sua vida. In: NÓVOA, A. (Org.). Vidas de professores. Porto: Porto Editora, 1992.

NÒVOA. A. Desafios do trabalho de professor no mundo contemporâneo. SINPRO-SP. 2007. Disponível em: <http://www.sinprosp.org.br/arquivos/novoa/livreto_novoa. pdf. >. Acesso em: 12 jul. 2011.

PAZ, M. L. da. A construção da identidade profissional de professores de matemática. o caso dos egressos do programa especial de formação pedagógica de docentes do Cefet - MG. In: ENCONTRO NACIONAL DE EDUCAÇÃO MATEMÁTICA, 9 - IX ENEM: Diálogo entre a Pesquisa e a Prática Educativa, 2007, Belo Horizonte. Anais... Belo Horizonte: SBEM/MG, 2007.

Disponível em:<www.sbem.com.br/files/ix_enem/Poster/Trabalhos/PO04350133607T.doc >. Acesso: 20 ago. 2015.

SAMPAIO, A. A. Programa de apoio ao bem-estar docente: construção profissional e cuidar de si. 2008. 174 f. Dissertação (Mestrado) - Pontifícia Universidade Católica do Rio Grande do Sul, Porto Alegre, 2008.

SAMPAIO, A. A. Vivências de docentes e de seus licenciandos no final de formação e passagem para o mundo do trabalho: mal/bem-estar docente/discente, autoimagem e autoestima. 2014. Tese (Doutorado) - Pontifícia Universidade Católica do Rio Grande do Sul, Porto Alegre, 2014.

SAMPAIO, A. A.; STOBAUS, C. D. Programa de apoio ao bem-estar docente: resultados quantitativos passados dois anos de seu desenvolvimento In: SEMINÁRIO NACIONAL DE EDUCAÇÃO, 2., 2009, Francisco Beltrão, PR; SEMANA DE PEDAGOGIA, 13., 2009, Francisco Beltrão, PR. Anais... Francisco Beltrão: Unioeste, 2009. p. 1-11. 
Avaliação qualitativa de programa de apoio ao bem-estar docente. In: SIMPÓSIO NACIONAL DE EDUCAÇÃO, 2., 2010, Cascavel, PR; SEMANA DE PEDAGOGIA, 21., 2010, Cascavel, PR. Anais... Cascavel: UNIOESTE, 2010. p. 1-13.

SANTINI, Joarez. Síndrome do esgotamento profissional: o "abandono" da carreira docente pelos professores de Educação Física da rede municipal de ensino de Porto Alegre. 2004. Dissertação (Mestrado) - Universidade Federal do Rio Grande do Sul, UFRGS, Porto Alegre, 2004 .

SANTOS, B. S. et al. Oficinas de conhecimento e motivação docente. In: SANTOS, Bettina S.; ANTUNES, D. D.; BERNARDI, J. (Org.). Processos motivacionais em contextos educativos. Malgualde/Ramada: Edições Pedago, 2012.

SCHÖN, D. A. Educando o profissional reflexivo: um novo design para o ensino e a aprendizagem. Porto Alegre: Artmed, 2000.

SOUSA, C. Educação para a resiliência. Tavira: Município de Tavira-PT, 2006.

TARDIFF, M.; LESSARD, C. O trabalho docente: elementos para uma teoria da docência como profissão de interações humanas. Petrópolis, RJ: Vozes, 2005.

THIELE, M. E. B.; AHLERT, Al. Condições de trabalho docente: um olhar na perspectiva do acolhimento. Estado do Paraná - Programa de Desenvolvimento Educacional (PDE). UNIOESTE, $2009 . \quad$ Disponível em: <http://www.diaadiaeducacao.pr.gov.br/portals/pde/arquivos/857-4.pdf>. Acesso em: 22 jan. 2016.

VÁSQUEZ, A. S. Filosofia da práxis. Buenos Aires: Conselho Latinoamericano de Ciências Sociais; São Paulo: Expressão Popular, 2007.

Recebido em: 05/07/2016

Revisado em: 05/04/2017

Aprovado em: 22/05/2017

Endereço para correspondência:

adelarsampaio@ hotmail.com

Adelar Aparecido Sampaio

Universidade Estadual do Oeste do Paraná

R. Universitária, 1619 - Universitário

Cascavel - PR - Brasil

CEP: 85819-110 